\title{
MENINGKATKAN KETERAMPILAN BERBICARA BAHASA ARAB MELALUI PERMAINAN BAHASA ISYRUNA SUALAN
}

\author{
Aisyatul Hanun $^{1}$, Herizal $^{2}$ \\ ${ }^{1}$ Universitas Ibrahimy Situbondo \\ ${ }^{2}$ UIN Maulana Malik Ibrahim Malang \\ ${ }^{1}$ aisyah_alfaqieroh@yahoo.com, ${ }^{2}$ icaals86@gmail.com
}

\begin{abstract}
The purpose of this research is to knowing the application of the game isyruna sualan in enhancing language skills of speaks Arabic for students class VII ${ }^{\mathrm{A}}$ MTsN 12 Banyuwangi 2018/2019 academic year. The fundamental problem is the low students on his willingness to learn arabic. The approach of this study used research a class action. The subject of this research are students and teachers of arabic language in class VII ${ }^{\mathrm{A}}$ MTsN 12 banyuwangi. The data that used in this research are picture, lesson plans, syllabus ,result of the lessons and records of interviews. Data collection techniques with observation, , interview, documentation and also tests. The procedure of this study using models from kurt lewin, has to encompass, planning the act of, observation and the reflections.The results found was the enhancing "hiwar" lessons with matter "baiti" use games language "isyruna sualan" after through two cycle with the details of the improvement of $76,41 \%$ be $78,43 \%$. work completed.
\end{abstract}

Keywords: Speaks Arabic, Game Isyruna Sualan

\section{PENDAHULUAN}

Bahasa Arab sebagai bahasa asing di Indonesia menempati posisi yang setrategis, terutama bagi umat muslim di Indonesia. Hal ini bukan saja karena Bahasa Arab digunakan dalam ritual keagamaan seperti sholat, khutbah jum'at, do'a, dan lain sebagainya, namun juga sebagai bahasa ilmu pengetahuan serta bahasa pergaulan internasional.

Sebagaimana kita ketahui bahwa, tujuan mendasar dalam belajar Bahasa Arab adalah memahami keterampilan yang empat. Sseperti keterampilan mendengar, berbicara, membaca, dan menulis. Tujuan mempelajarinya siswa memiliki kompetensi membaca Al-qur'an dan hadis-hadis nabi yang mulia, memahami keduanya adalah faktor utama dalam belajar agama islam, kitab-kitab agama dan ilmu lainnya. Berdasarkan hal tersebut siswa mampu berkomunikasi dengan yang lain baik secara langsung dan tidak langsung.

Keterampilan berbicara adalah cabang dari cabang bahasa yang empat. Berbicara ialah terjemahan lisan serta cara seseorang untuk belajar istimak, membaca dan menulis.
Berbicara adalah simbol untuk membedakan setiap manusia. Maka bukanlah tiap-tiap suara itu kalam karena kalam ialah terdiri dari suara dan memberi pemahaman. Lafaz adalah suara yang mencangkup atas sebagian huruf-huruf hija'iyah. Faidah adalah suatu yang menujukkan atas makna dari suatu makna. Sedikit sekali dari pemikiran pembicara. Benar, suara-suara yang terlintas dari sebagian hewan dan burung-burung yang mencangkup sebagian tanda untuk tempattempat yang dibutuhkan terhadap hewanhewan ini. Makna yang lain kadang dipahami akan tetapi seidkit yang berkaitan dengan kondisi yang ditentukan. ${ }^{1}$

Keterampilan berbicara memainkan peran penting bagi masyarakat modern tetapi juga untuk selanjutnya. Tidak ada keraguan bahwa ucapan adalah salah satu warna terpenting dari aktivitas bahasa untuk anak kecil dan dewasa. Orang-orang lebih banyak bicara daripada menulis, yaitu mereka

$$
\begin{aligned}
& \text { 1 } \\
& \text { هضة المصرية } 1990 \text { م )ن ص: } 105
\end{aligned}
$$


berbicara lebih banyak daripada menulis. ${ }^{2}$ Oleh karena itu, bicara dapat dianggap sebagai bentuk utama komunikasi linguistik bagi manusia dan oleh karena itu berbicara adalah bagian terpenting dari praktik dan penggunaan bahasa.

Kebanyaakan yang kami temukan, bawasanya mereka menjadikan pembelajaran Bahasa Arab sebagai tujuan utama dalam mengusai keterampilan berbicara dan bercakap-cakap, sebagaimana kami katakan (seperti, pulan mengetahui bahasa inngris).

Guru harus melakukan segala upaya untuk merangsang keinginan siswa untuk berbicara, berdiskusi, dan cenderung pada semus jenis komunikasi lisan. Sebagaimana seharusnya mengetahui strategi, metodemetode dan media pembelajaran yang dapat membantu siswa dalam mengembangkan kemampuan mereka dalam kegiatan bahasa. Guru yang mengelola metode-metode, strategi dan media pengajaran ini, Bahwa siswa tidak dapat belajar berbicara tanpa berbicara.

Karena keterampilan berbicara sangat penting dalam mencapai pengajaran Bahasa Arab, masing-masing gurunya harus memperhatikan masalah pendidikan dan peneliti strategi pencapaian, dan masalah setiap hambatan dalam pendidikan. Strategi pencapain adalah setiap rencana yang murni untuk dijalankan oleh guru Bahasa Arab dalam pendidikan serta untuk tujuan pendidikan. Berdasarkan masalah ini, bidang pendidikan membutuhkan cara dan media yang benar agar memiliki posisi tertiggi dalam pengajaran materi pelajaran, termasuk Bahasa Arab dan berdampak pada tingkat pencapaian/keberhasilan siswa. ${ }^{3}$ Salah satu metode pengajaran dalam pengajaran berbicara adalah permainan bahasa. Menurut soeparno (1987) permainan bahasa (language game) adalah suatu aktifitas memperoleh

$$
\begin{aligned}
& \text { 2عبد السيد، تعليم اللغة العبية، القاهرة: دار الفكر 2003م ) } \\
& \text { 10: ص } \\
& \text { 3رشدي أمد طعيمة، تعليم اللغة العربية لغير الناطقين مناهجه }
\end{aligned}
$$

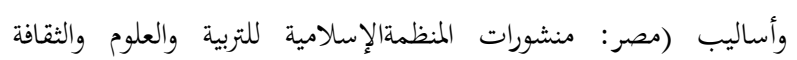

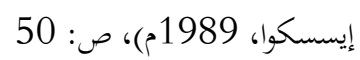

suatu keterampilan berbahasa tertentu dengan cara yang mengembirakan. Dengan demikian, permainan bahasa dapat diartikan sebagai suatu aktifitas atau kegiatan yang dimiliki aturan, tujuan dan mengandung unsur-unsur hiburan yang menyenangkan dan mengembirakan. ${ }^{4}$ permainan bahasa adalah cara mempelajari bahasa melalui permainan. Pada hakikatnya permainan bahasa adalah suatu aktifitas untuk memperoleh suatu keterampilan berbahasa tertentu dengan cara yang menggembirakan ${ }^{5}$

Permainan bahasa membantu membuat teks di mana bahasa tersebut berguna dan bermakna, menghasilkan keinginan peserta didik untuk berpartisipasi dan berkontribusi. Untuk melakukan ini, mereka harus memahami apa yang dikatakan atau ditulis orang lain, dan mereka juga harus berbicara dan menulis untuk mengekspresikan pandangan mereka. Dengan demikian, makna bahasa yang mereka dengar, baca, ucapkan dan tulis akan lebih hidup dan lebih mudah diingat.

Faktanya, banyak sekolah di Indonesia belum mencetak cara baru bagi siswa untuk mereka belajar kosa kata Arab. Bahkan media pembelajaran dari metode qawa'id, terjemah dan hafalan. kebanyakan prakik dan selainnya. Ini terjadi di sebagian besar sekolah di Indonesia.

Berdasarkan Hasil observasi di MTs Negeri 12 Banyuwangi, obsrvasi dilakukan dengan mengamati langsung kgiatan pembelajaran Bahasa Arab dan melalui wawancara dngan guru kelas VII ${ }^{\mathrm{A}}$ yaitu Imam Al-Ghozali. Hasil wawancara peneliti dengan guru kelas VII $^{\mathrm{A}}$ ada beberapa masalah yang masih dihadapi siswa dalam mengajarkan keterampilan berbicara, termasuk kurangnya kosa kata yang diserap oleh siswa, sulit bagi mereka untuk berbicara untuk mengungkapkan ide dan pendapat mereka dalam Bahasa Arab. Hilangnya sebagian

\footnotetext{
4 Mohammad Kholison Dan Risma Fathul Amin, Aneka Permainan Untuk Pembelajaran Bahasa Inngris Dan Arab, (malang:CV.LISAN ARABI 2018), Cet.1 Hal. 2-3.

5 Umi Machmudah, Abdul Wahab Rosyidi, Active Learning Dalam Pembelajaran Bahasa Arab, (Malang: UIN Malang Press, 2008), 175.
} 
kosakata yang diserap oleh siswa karena kurangnya penggunaan kosa kata dan latihan berbicara. Hal ini dapat dilihat dari nilai siswa yang diperoleh tidak mencapai kriteria ketuntasan minimal (KKM) dan KKM yang harus dicapai adalah 75 sedanagkan nilai yang diperoleh siswa terdapat kurang dari 20\% untuk mencapai KKM. Faktor yang meyebabkan siswa kurang mampu dalam berbicara Bahasa Arab adalah metode pembelajaran kurang bervariasi masih menoton pada metode ceramah dan pemahaman terhadap materi saja. Untuk meningkatkan kemampuan siswa dalam berbicara bahasa Arab, guru memiliki peran penting dalam mencapai setiap standar kompetensi (SK) dan kompetensi dasar (KD) yang ditentuka. Guru dituntut sekreatif mungkin menciptakan suasana yang aktif. Model yang digunakan untuk meningkatan keterampilan berbicara siswa adalah permainan bahasa isyruna sualan dengan menerapkan permianan bahasa ini dapat menigkatkan kemampuan berbicara Bahasa Arab siswa. Permainan bahasa isyruna sualan adalah permainan yang berorientasi pada penguasaan materi dan dapat meningkatkan keterampilan berbicara dengan cara siswa dituntut untuk menebak kosa kata (mufrodat) yang telah disiapkan oleh guru dengan cara mempertanyakannya. ${ }^{6}$. berkaitan dengan uraian sebelumnya, penelitian ini memfokuskan pembahasannya pada meningkatkan keterampilan berbicara Bahasa Arab dengan permainan bahasa isyruna sualan oleh siswa MTs Negeri 12 Banyuwangi Tahun Pelajaran 2018/2019. Kelas merupakan suatu cara memperbaiki dan meningkatkan layanan pendidikan yang diselenggarakan dalam peningkatan kualitas program sekolah secara keseluruhan. Penelitian tindakan kelas merupakan penekanan pada kegiatan (tindakan) melalui uji coba ide keadaan praktik atau situasi yang diharapkan. Kegiatan tersebut mampu

6 ناصف مصطفى عبج العزيز، الألعاب اللغوية في تعليم اللغة الأجنبية، (الرياض : دار

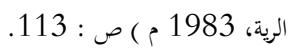

memperbaiki dan meningkatkan kualitas proses belajar mengajar di kelas. ${ }^{7}$

\section{METODE PENELITIAN}

Penelitian ini menggunakan PTK, dengan subjek merupakan siswa kelas $\mathrm{VII}^{\mathrm{A}}$ MTs Negeri 12 Banyuwangi yang berjumlah 31 orang, terdiri dari 15 orang siswa laki-laki dan 16 orang siswa perempuan. Selanjutnya objek penelitian ini adalah kemampuan berbicara Bahasa Arab kelas VII ${ }^{\mathrm{A}}$ MTs Negeri 12 banyuwangi. Teknik pengumpulan meliputi: Observasi, Wawancara, Dokumentasi, dan Tes ${ }^{8}$

\section{HASIL PENELITIAN DAN PEMBAHASAN}

Penelitian dilaksanakan di kelas VII $^{\mathrm{A}}$ MTs Negeri 12 Banyuwangi dengan berjumlah 31 orang yang terdiri dari 15 orang siswa laki-laki dan 16 orang siswa perempuan, hasil diperoleh dari tes dan non tes. Hasil tes berasal dari praiklus, siklus I, dan siklus II. Hasil tes tindakan prasiklus, siklus I dan siklus II merupakan keterampilan berbicara bahasa aran dengan permainan bahasa isyruna sualan. Hasil tes prasiklus berupa keterampilan berbicara bahasa arab sebelum penelitian dilaksanakan.

TABEL 1: pemerolehan nilai siklus I kemampuan berbicara Bahasa Arab

\begin{tabular}{|c|c|c|c|c|c|c|c|c|c|}
\hline \multirow[b]{2}{*}{$\begin{array}{l}\mathrm{N} \\
\mathrm{O}\end{array}$} & \multirow[b]{2}{*}{ Nama } & \multicolumn{5}{|c|}{ Skor } & \multirow[t]{2}{*}{ E. } & \multicolumn{2}{|c|}{$\begin{array}{l}\text { keteranga } \\
\mathrm{n}\end{array}$} \\
\hline & & 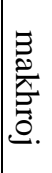 & 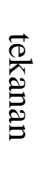 & 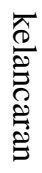 & 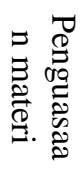 & 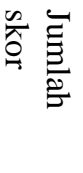 & & $\underset{\tilde{\#}}{\stackrel{\Xi}{\Xi}}$ & 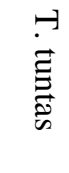 \\
\hline 1 & $\begin{array}{l}\text { Afif } \\
\text { Amrullah }\end{array}$ & 3 & 3 & 3 & 3 & 12 & 75 & $\mathrm{x}$ & \\
\hline 2 & $\begin{array}{l}\text { Alfian } \\
\text { Faturohm } \\
\text { an }\end{array}$ & 2 & 3 & 3 & 3 & 11 & 69 & & $\mathrm{x}$ \\
\hline 3 & Amelya & 4 & 3 & 4 & 4 & 15 & 94 & $\mathrm{x}$ & \\
\hline
\end{tabular}

Gomos GraceN Sianturi, dkk, "Menigkatkan Kemampuan Menulis Teks Berita Dengan Model Pembelajaran Kooperatif Tife Stad (Student Team Achievement Divisions)", TAPANULI JOURNALS Vol. 1 No. 2, 2019, Hal 358

8 E. Mulyasa, Kurikulum Berbasis Kompetensi, (Bandung: Remaja Rosdakarya, 2005). Hal 100. 


\begin{tabular}{|c|c|c|c|c|c|c|c|c|c|c|c|c|c|c|c|c|c|c|c|}
\hline & Vega & & & & & & & & & 3 & Indah & & & & & & & & \\
\hline & Cindya & & & & & & & & & & Cahyani & & & & & & & & \\
\hline & $\begin{array}{l}\text { Novi } \\
\text { Ranadha }\end{array}$ & & & & & & & & & \begin{tabular}{l|}
2 \\
4 \\
\end{tabular} & $\begin{array}{l}\text { Rendi } \\
\text { Afrianto }\end{array}$ & 3 & 3 & 3 & 3 & 12 & 75 & $\mathrm{x}$ & \\
\hline 4 & $\begin{array}{l}\text { ni } \\
\text { Fatikasar } \\
\text { i }\end{array}$ & 3 & 2 & 3 & 4 & 12 & 75 & $\mathrm{x}$ & & \begin{tabular}{l|}
2 \\
5
\end{tabular} & $\begin{array}{l}\text { Robbil } \\
\text { Nurahma } \\
\mathrm{n}\end{array}$ & 2 & 3 & 3 & 3 & 11 & 69 & & $\mathrm{x}$ \\
\hline 5 & $\begin{array}{l}\text { Dewi } \\
\text { Puspita }\end{array}$ & 4 & 4 & 3 & 3 & 14 & 88 & $\mathrm{x}$ & & \begin{tabular}{l|}
2 \\
6 \\
\end{tabular} & $\begin{array}{l}\text { Rofiatul } \\
\text { Insiana }\end{array}$ & 4 & 2 & 3 & 3 & 12 & 75 & $\mathrm{x}$ & \\
\hline & & & & & & & & & & 2 & & & & & & & & & \\
\hline 6 & $\begin{array}{l}\text { Diyan } \\
\text { Dwi }\end{array}$ & 2 & 4 & 3 & 4 & 13 & 81 & $\mathrm{x}$ & & 7 & $\begin{array}{l}\text { Yoga } \\
\text { Pratama }\end{array}$ & 2 & 2 & 2 & 3 & 9 & 56 & & $\mathrm{x}$ \\
\hline & Safitri & & & & & & & & & $\begin{array}{l}2 \\
8\end{array}$ & $\begin{array}{l}\text { Syahdan } \\
\text { Amrullah }\end{array}$ & 3 & 2 & 3 & 4 & 12 & 75 & $\mathrm{x}$ & \\
\hline 7 & $\begin{array}{l}\text { Dwi } \\
\text { Hildayat } \\
\text { us }\end{array}$ & 2 & 4 & 2 & 3 & 11 & 69 & & $\mathrm{x}$ & \begin{tabular}{l|}
2 \\
9 \\
\end{tabular} & $\begin{array}{l}\text { Tio } \\
\text { Rifaldi }\end{array}$ & 3 & 3 & 3 & 3 & 12 & 75 & $\mathrm{x}$ & \\
\hline & Sholehah & & & & & & & & & 3 & Vendi & & & & & & & & \\
\hline 8 & $\begin{array}{l}\text { Dwi } \\
\text { Okta }\end{array}$ & 4 & 3 & 3 & 3 & 13 & 81 & $\mathrm{x}$ & & 0 & $\begin{array}{l}\text { Dwi } \\
\text { Prayoga }\end{array}$ & 2 & 2 & 3 & 4 & 11 & 69 & & $\mathrm{x}$ \\
\hline & Nadifa & & & & & & & & & 3 & Zakiah & & & & & & & & \\
\hline 9 & $\begin{array}{l}\text { Fais } \\
\text { Zatul }\end{array}$ & 4 & 3 & 3 & 4 & 14 & 88 & $\mathrm{x}$ & & 1 & $\begin{array}{l}\text { Fatin } \\
\text { Nabila }\end{array}$ & 2 & 3 & 3 & 3 & 11 & 69 & & $\mathrm{x}$ \\
\hline & Wasia & & & & & & & & & & & & & & & & & 20 & 11 \\
\hline 1 & $\begin{array}{l}\text { Faradilla } \\
\text { Arisya }\end{array}$ & 4 & 4 & 4 & 4 & 16 & 10 & $\mathrm{x}$ & & & Jumlah & & & & & & $\begin{array}{l}23 \\
69 \\
\end{array}$ & & \\
\hline & Azwa & & & & & & & & & & & & & & & & & & \\
\hline & Fendra & & & & & & & & & & Table 2: & & 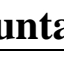 & & bel & ar sil & us I & & \\
\hline $\begin{array}{l}1 \\
1\end{array}$ & $\begin{array}{l}\text { Ardiyans } \\
\text { yah }\end{array}$ & 3 & 2 & 2 & 3 & 10 & 63 & & $\mathrm{x}$ & & Nilai ra & $a-r$ & ta $t$ & & $\bar{X}=$ & & $\bar{X}$ & $=\frac{23}{3}$ & $\frac{69}{1}=$ \\
\hline 1 & $\begin{array}{l}\text { Herlamb } \\
\text { ang Diky }\end{array}$ & 2 & 2 & 4 & 4 & 12 & 75 & $\mathrm{x}$ & & & siswa & & & & 76. & & & & \\
\hline 2 & Satriyo & & & & & & & & & & Jumlah & & sis & & 20 & & & & \\
\hline 1 & Itsna & & & & & & & & & & yang tun & & & & & & & & \\
\hline 3 & $\begin{array}{l}\text { Elsyarifd } \\
\text { a al-Fathi }\end{array}$ & 4 & 4 & 4 & 4 & 16 & 0 & $\mathrm{x}$ & & & & & & & $\underline{\sum S}$ & vay & $n g t$ & unta & s bela \\
\hline $\begin{array}{l}1 \\
4 \\
\end{array}$ & $\begin{array}{l}\text { Ivan Aril } \\
\text { Setiawan }\end{array}$ & 2 & 3 & 2 & 3 & 10 & 63 & & $\mathrm{x}$ & & $\begin{array}{l}\text { Persenta } \\
\text { ketuntas }\end{array}$ & an & elaj & & 20 & 10 & $\mathrm{Sis}$ & $w a$ & \\
\hline 1 & $\begin{array}{l}\text { M . Fani } \\
\text { Rahmadi }\end{array}$ & 3 & & & 4 & & 75 & & & & & & & & $\overline{31}$ & & & & \\
\hline
\end{tabular}

Dari tabel di atas, diketahui bahwa nilai rata-rata tes pemahaman siswa terhadap materi baiti bahasa Arab pada siklus I adalah 76.41 sedangkan persentase ketuntasan belajar siswa adalah $64.52 \%$. Ketuntasan belajar pada siklus I masuk dalam kriteria kurang.

Tabel 3: pemerolehan nilai siklus II kemampuan berbicara Bahasa Arab

\begin{tabular}{|c|c|c|c|c|c|c|c|c|c|}
\hline & \multirow[b]{2}{*}{ Nama } & \multicolumn{5}{|c|}{ skor } & \multirow[b]{2}{*}{ E. } & \multicolumn{2}{|c|}{$\begin{array}{l}\text { ketera } \\
\text { ngan }\end{array}$} \\
\hline $\begin{array}{l}\mathrm{N} \\
\mathrm{N}\end{array}$ & & 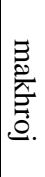 & 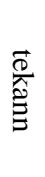 & 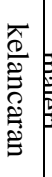 & : & 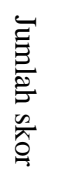 & & 䲩 & $\begin{array}{l}\overrightarrow{\vec{E}} \\
\overrightarrow{\vec{E}}\end{array}$ \\
\hline 1 & Afif Amrullah & 3 & 3 & 3 & 4 & 13 & 81 & $\mathrm{x}$ & \\
\hline
\end{tabular}




\begin{tabular}{|c|c|c|c|c|c|c|c|c|c|}
\hline 2 & $\begin{array}{l}\text { Alfian } \\
\text { Faturohman }\end{array}$ & 2 & 3 & 3 & 3 & 11 & 69 & & $\mathrm{x}$ \\
\hline 3 & Amelya Vega & 4 & 3 & 4 & 4 & 15 & 94 & $\mathrm{x}$ & \\
\hline 4 & $\begin{array}{l}\text { Cindya Novi } \\
\text { Ranadhani } \\
\text { Fatikasari }\end{array}$ & 3 & 2 & 4 & 4 & 13 & 81 & $\mathrm{x}$ & \\
\hline 5 & $\begin{array}{ll}\text { Dewi } & \text { Puspita } \\
\text { Sari } & \\
\end{array}$ & 4 & 4 & 3 & 3 & 14 & 88 & $\mathrm{x}$ & \\
\hline 6 & $\begin{array}{l}\text { Diyan } \\
\text { Safitri }\end{array}$ & 2 & 3 & 3 & 4 & 12 & 75 & $\mathrm{x}$ & \\
\hline 7 & $\begin{array}{l}\text { Dwi Hildayatus } \\
\text { Sholehah }\end{array}$ & 2 & 4 & 4 & 3 & 13 & 81 & $\mathrm{x}$ & \\
\hline 8 & $\begin{array}{ll}\text { Dwi } & \text { Okta } \\
\text { Nadifa } & \\
\end{array}$ & 4 & 3 & 3 & 3 & 13 & 81 & $\mathrm{x}$ & \\
\hline 9 & $\begin{array}{ll}\text { Fais } & \text { Zatul } \\
\text { Wasia } & \\
\end{array}$ & 2 & 3 & 3 & 4 & 12 & 75 & $\mathrm{x}$ & \\
\hline $\begin{array}{l}1 \\
0\end{array}$ & $\begin{array}{l}\text { Faradilla Arisya } \\
\text { Azwa }\end{array}$ & 4 & 4 & 4 & 4 & 16 & $\begin{array}{l}10 \\
0\end{array}$ & $\mathrm{x}$ & \\
\hline $\begin{array}{l} \\
1 \\
\end{array}$ & $\begin{array}{l}\text { Fendra } \\
\text { Ardiyansyah }\end{array}$ & 3 & 3 & 2 & 4 & 12 & 75 & $\mathrm{x}$ & \\
\hline $\begin{array}{l}1 \\
2 \\
\end{array}$ & $\begin{array}{l}\text { Herlambang } \\
\text { Diky Satriyo }\end{array}$ & 2 & 2 & 4 & 4 & 12 & 75 & $\mathrm{x}$ & \\
\hline $\begin{array}{l}1 \\
3\end{array}$ & $\begin{array}{l}\text { Itsna Elsyarifda } \\
\text { al-Fathi }\end{array}$ & 4 & 4 & 4 & 4 & 16 & $\begin{array}{l}10 \\
0\end{array}$ & $\mathrm{x}$ & \\
\hline $\begin{array}{l}1 \\
4 \\
\end{array}$ & $\begin{array}{ll}\text { Ivan } & \text { Aril } \\
\text { Setiawan } & \\
\end{array}$ & 2 & 4 & 2 & 4 & 12 & 75 & $\mathrm{x}$ & \\
\hline $\begin{array}{l}1 \\
5 \\
\end{array}$ & $\begin{array}{l}\text { M F Fani } \\
\text { Rahmadian }\end{array}$ & 4 & 2 & 2 & 4 & 12 & 75 & $\mathrm{x}$ & \\
\hline $\begin{array}{l}1 \\
6 \\
\end{array}$ & $\begin{array}{l}\text { Mohammad } \\
\text { Taufiq Hidayat }\end{array}$ & 2 & 4 & 3 & 3 & 12 & 75 & $\mathrm{x}$ & \\
\hline $\begin{array}{l}1 \\
7 \\
\end{array}$ & $\begin{array}{l}\text { Nabila Ulfa } \\
\text { Mauladani }\end{array}$ & 3 & 3 & 4 & 4 & 14 & 88 & $\mathrm{x}$ & \\
\hline $\begin{array}{l}1 \\
8 \\
\end{array}$ & $\begin{array}{l}\text { Navida } \\
\text { Salsabila } \\
\end{array}$ & 3 & 4 & 4 & 4 & 15 & 94 & $\mathrm{x}$ & \\
\hline $\begin{array}{l}1 \\
9 \\
\end{array}$ & Nova al-Farizy & 2 & 3 & 4 & 3 & 12 & 75 & $\mathrm{x}$ & \\
\hline $\begin{array}{l}2 \\
0\end{array}$ & Nur Rohman & 3 & 3 & 3 & 2 & 11 & 69 & & $\mathrm{x}$ \\
\hline $\begin{array}{l}2 \\
1\end{array}$ & $\begin{array}{l}\text { Nurul Fadilatus } \\
\text { Soleha }\end{array}$ & 3 & 3 & 3 & 3 & 12 & 75 & $\mathrm{x}$ & \\
\hline $\begin{array}{l}2 \\
2 \\
\end{array}$ & $\begin{array}{l}\text { Putri Amelia } \\
\text { Faulina }\end{array}$ & 3 & 3 & 4 & 2 & 12 & 75 & $\mathrm{x}$ & \\
\hline $\begin{array}{l}2 \\
3 \\
\end{array}$ & $\begin{array}{ll}\text { Putri } & \text { Indah } \\
\text { Cahyani } & \\
\end{array}$ & 4 & 4 & 2 & 2 & 12 & 75 & $\mathrm{x}$ & \\
\hline $\begin{array}{l}2 \\
4 \\
\end{array}$ & Rendi Afrianto & 3 & 3 & 3 & 3 & 12 & 75 & $\mathrm{x}$ & \\
\hline $\begin{array}{l}2 \\
5\end{array}$ & $\begin{array}{l}\text { Robbil } \\
\text { Nurahman }\end{array}$ & 2 & 3 & 4 & 2 & 11 & 69 & & $\mathrm{x}$ \\
\hline $\begin{array}{l}2 \\
6 \\
\end{array}$ & Rofiatul Insiana & 2 & 3 & 2 & 4 & 11 & 69 & & $\mathrm{x}$ \\
\hline $\begin{array}{l}2 \\
7 \\
\end{array}$ & $\begin{array}{ll}\text { Sendi } & \text { Yoga } \\
\text { Pratama } & \\
\end{array}$ & 4 & 2 & 4 & 3 & 13 & 81 & $\mathrm{x}$ & \\
\hline $\begin{array}{l}2 \\
8 \\
\end{array}$ & $\begin{array}{l}\text { Syahdan } \\
\text { Amrullah }\end{array}$ & 3 & 2 & 2 & 4 & 11 & 69 & & $\mathrm{x}$ \\
\hline $\begin{array}{l}2 \\
9 \\
\end{array}$ & Tio Rifaldi & 4 & 2 & 3 & 4 & 13 & 81 & $\mathrm{x}$ & \\
\hline $\begin{array}{l}3 \\
0\end{array}$ & $\begin{array}{ll}\text { Vendi } & \text { Dwi } \\
\text { Prayoga } & \\
\end{array}$ & 3 & 3 & 2 & 3 & 11 & 69 & & $\mathrm{x}$ \\
\hline $\begin{array}{l}3 \\
1 \\
\end{array}$ & $\begin{array}{l}\text { Zakiah } \text { Fatin } \\
\text { Nabila }\end{array}$ & 3 & 2 & 3 & 3 & 11 & 69 & & $\mathrm{x}$ \\
\hline & Jumlah & & & & & & $\begin{array}{l}24 \\
31\end{array}$ & $\begin{array}{l}2 \\
4\end{array}$ & 7 \\
\hline
\end{tabular}

\begin{tabular}{|l|l|}
\hline tuntas & \\
\hline $\begin{array}{l}\text { Persentase } \\
\text { ketuntasan } \\
\text { belajar }\end{array}$ & $\frac{\sum \text { Siswa yang tuntas belajd }}{\sum \text { Siswa }}$ \\
\hline
\end{tabular}

Dari tabel di atas, dapat diketahui nilai rata-rata tes kemampuan siswa dalam memahami baiti bahasa Arab pada siklus II sebesar 78.43. Sedangkan persentase ketuntasan belajar siswa sebesar $77.42 \%$ Kentuntasan belajar pada siklus II ini masuk dalam kriteria cukup.

Tabel 5: Hasil Pemahaman baiti Bahasa Arab dengan Menggunakan permainan bahasa isyruna sualan

\begin{tabular}{|c|c|c|c|c|}
\hline N & Aspek & Siklus I & $\begin{array}{c}\text { Siklus } \\
\text { II }\end{array}$ & Peningkatan \\
\hline 1 & $\begin{array}{l}\text { Rata- } \\
\text { rata } \\
\text { kelas }\end{array}$ & 76,41 & 78,43 & $\begin{array}{l}\text { Pra-Siklus ke } \\
\text { siklus I = 4,64 } \\
\text { Siklus I ke } \\
\text { siklus II = } 2,02\end{array}$ \\
\hline 2 & $\begin{array}{l}\text { Ketun } \\
\text { tasan } \\
\text { belaja } \\
\mathrm{r}\end{array}$ & $\begin{array}{l}64,52 \\
\%\end{array}$ & $\begin{array}{l}77,42 \\
\%\end{array}$ & $\begin{array}{llr}\text { Pra-Siklus } & \text { ke } \\
\text { siklus } & \text { I } & = \\
19,36 \% & & \\
\text { Siklus } & \text { I } & \text { ke } \\
\text { siklus } & \text { II } & = \\
12,9 \% & & \\
\end{array}$ \\
\hline
\end{tabular}

Dari tabel di atas dapat diketahui bahwa telah terjadi peningkatan pemahaman baiti bahasa Arab dengan menggunakan permainan bahasa "isyruna sualan". Peningkatan tersebut terjadi dalam dua aspek, yakni (1) aspek rata-rata kelas dari siklus I ke siklus II terjadi peningkatan sebesar 2,02\%. (2) aspek ketuntasan belajar dari siklus I ke siklus II terjadi peningkatan persentase sebesar $12,9 \%$.

Table 4: Ketuntasan belajar siklus II

\begin{tabular}{|l|l|}
\hline $\begin{array}{l}\text { Nilai rata- } \\
\text { rata tes } \\
\text { siswa }\end{array}$ & $\begin{array}{l}\bar{X}=\frac{\sum X}{\sum N} \\
78.43\end{array} \quad \rightarrow \quad \bar{X}=\frac{2431}{31}=$ \\
\hline $\begin{array}{l}\text { Jumlah } \\
\text { siswa yang }\end{array}$ & 24 \\
\hline
\end{tabular}




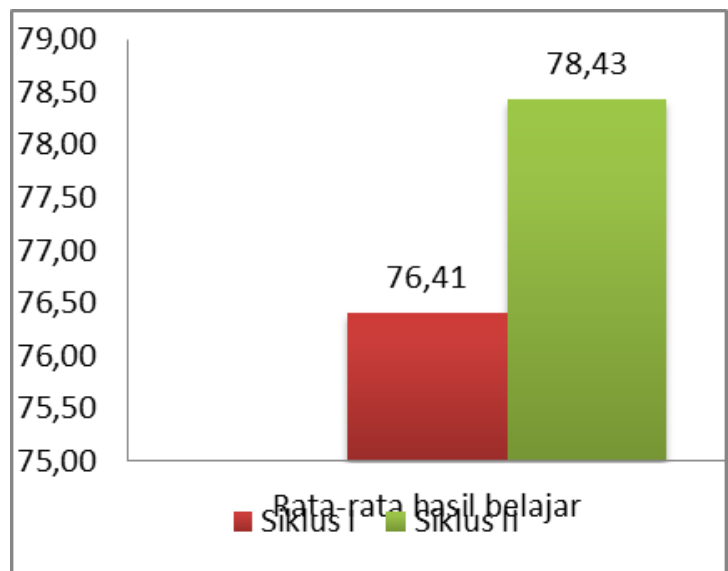

Gambar 2 : Peningkatan Hasil Nilai Tes

Siklus I dan Siklus II dalam pemahanan baiti dalam meningkatkan keterampilan berbicara Bahasa Arab Siswa Kelas VII ${ }^{\mathrm{A}}$ MTs 12 Banyuwangi.

Dari diagram batang di atas, dapat disimpulkan bahwa persentase ketuntasan belajar siswa mengalami peningkatan pada tiap siklusnya. pada siklus I terjadi peningkatan sebesar $19,36 \%$ sehingga persentase ketuntasan belajar menjadi 64,52\%. Pada siklus II, peningkatannya adalah sebesar $12,9 \%$. Ketuntasan belajar pada siklus II adalah sebesar 77,42\%.

\section{SIMPULAN}

Berdasarkan hasil peelitian, dan pembahasan dalam penelitian, dapat disimpulakan sebagai berikut

1. Proses pembelajaran kalam dengan menggunakan permainan bahasa isyruna sualan pengalamai penigkatan. Peningkatan tersebut pada proses pembelajaran hiwar dengan materi baiti dengan menggunakan permainan bahasa isyruna sualan. Selama proses pembelajaran keadaan kelas agak sedidkit rebut karena bentuknya permainan dan serius dalam belajar, siswa merasa senang dan antusias terhadap materi pembelajaran kalam dengan materi baiti.

2. Hasil pembelajaran bahasa arab dengan materi baiti siswa kelas VII $^{\mathrm{A}}$ MTs Negeri 12 Banyuwangi meningkat setelah mengikuti pembelajaran dengan menggunakan permainan bahasa isyruna sualan. Siswa yang mampu mencapai nilai kriteria ketuntasan minimal pada siklus I sebanyak 20 anak $(76,41 \%)$ sisw, sedangkan pada siklus II sebanyak 24 $(78,43 \%)$ siswa.

3. Ada peningkatan hasil pembelajaran kemampuan berbicara Bahasa Arab dengan permainan bahasa isyruna sualan. Terbukti dengan nilai di siklus I $(76,41 \%)$ dan siklus II $(78,43 \%)$.

\section{DAFTAR PUSTAKA}

$$
\begin{aligned}
& \text { محمد إبراهيم عطا، طرق التدريس اللغة العربية. } \\
& 1990 \text { م. القاهرة : مكتبة هضة المصرية } \\
& \text { عبد السيد. 2003م. تعليم اللغة العربية. القاهرة }
\end{aligned}
$$

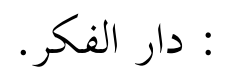

$$
\begin{aligned}
& \text { رشدي أحمد طعيمة. 2003. المهارات }
\end{aligned}
$$

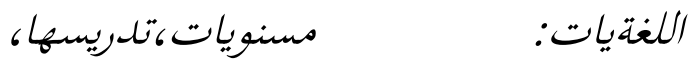

$$
\begin{aligned}
& \text { صعوبتها.القاهر: دار الفكر العربي. } \\
& \text { ناصف مصطفى عبد العزيز. 1981م. الألعاب } \\
& \text { اللغوية في تعليم اللغة الأجنبية. الرياض: } \\
& \text { دار الرية. }
\end{aligned}
$$

E. Mulyasa, 2005, Kurikulum Berbasis Kompetensi, Bandung: Remaja Rosdakarya

Dr. Mhd. Ashar, 2019, upaya menigkatkan aktivitas belajar peserta didik pada permainan bola voli melalui penerapan modivikasi pembelajaran di kelas, Jurnal Menara Ilmu, Vol. XIII No. 5

Gomos GraceN Sianturi, dkk, 2019, Menigkatkan Kemampuan Menulis Teks Berita Dengan Model Pembelajaran Kooperatif Tife Stad (Student Team Achievement Divisions), tapanuli journals Vol. 1 No. 2

Kunandar, 2011, Langkah Mudah Penelitian Tindakan Kelas Sebagai Pengembangan Profesi Guru, Jakarta: Raja Grafindo Persada 
Mohammad Kholison Dan Risma Fathul Amin, 2018, Aneka Permainan Untuk Pembelajaran Bahasa Inngris Dan Arab, malang:CV.LISAN ARABI, Cet. 1

Suharsimi Arikunto, dkk., 2007, Penelitian Tindakan Kelas Jakarta: Bumi Aksara

Umi Machmudah, Abdul Wahab Rosyidi, 2008, Active Learning Dalam Pembelajaran Bahasa Arab, Malang: UIN Malang Press

Zainal Aqib, , 2007, Penelitian Tindakan Kelas untuk Guru, Bandung: Yrama Widya 